\title{
Qualidade de feijão-vagem minimamente processado em função das operações de enxague e sanificação
}

\section{Quality of minimally processed snap bean in function of rinse and sanification operations}

\author{
José Eduardo Peres ${ }^{1}$; Maria Cecília Arruda ${ }^{2 *}$; Mirian Souza Fileti ${ }^{3}$; Ivan Herman \\ Fischer $^{2}$; Eliane Maria Ravasi Stéfano Simionato ${ }^{4}$; Diego Scacalossi Voltan ${ }^{5}$
}

\section{Resumo}

Este trabalho teve como objetivo avaliar a qualidade de vagens minimamente processadas em função das operações de enxague e sanificação. Vagens cv. Itatiba 2 foram selecionadas, higienizadas, processadas e submetidas aos seguintes tratamentos: T1 - enxágue somente em água, T2 - enxágue em água, seguido de imersão em solução clorada $\left(100 \mathrm{mg} . \mathrm{L}^{-1}\right)$ por 5 minutos, T3 - imersão em solução clorada (100 mg.L $\left.\mathrm{L}^{-1}\right)$ por 5 minutos e T4 - sem enxágue e sem imersão em solução clorada (controle). As vagens minimamente processadas foram avaliadas quanto à aparência, coloração da superfície de corte e aspectos microbiológicos. Em relação à coloração da superfície de corte, observou-se a partir do nono dia de armazenamento que as vagens do Tratamento 1 apresentaram menor escurecimento em relação às dos demais tratamentos, sendo também melhor aceitas sensorialmente. Salmonella e coliformes a $45^{\circ} \mathrm{C}$ não foram detectados em nenhuma amostra dos diferentes tratamentos. Em relação à contagem de coliformes totais observou-se no dia do processamento redução com a sanificação (T2 e T3) e em geral, aumento dos coliformes durante o armazenamento. A contagem total de bactérias psicrotróficas foi $>$ $10^{5}$ UFC. $\mathrm{g}^{-1}$ nas vagens de todos os tratamentos no sexto dia de armazenamento, exceto naquele onde as vagens foram enxaguadas e sanificadas. Portanto, este tratamento é recomendado e garante às vagens minimamente processadas vida útil de até seis dias, limitada pelo crescimento de bactérias.

Palavras-chave: Phaseolus vulgaris L, processamento mínimo, cloro, bactérias, escurecimento

\begin{abstract}
This work had the purpose to evaluate the quality of the minimally processed snap bean in function of rinse and sanification operations. Snap bean cv. Itatiba 2 were selected, cleaned, processed and submitted to the following treatments: T1 - rinse in water only, T2 - rinse in water, followed by immersion in chlorinated solution (100 mg.L $\left.\mathrm{L}^{-1}\right)$ for 5 minutes, T3 - immersion in chlorinated solution $\left(100 \mathrm{mg} . \mathrm{L}^{-1}\right)$ for 5 minutes and $\mathrm{T} 4$ - without rinse and without immersion in chlorinated solution (control). The minimally processed snap beans were assessed for appearance, color of the section surface and microbiological characteristics. About the color of the section surface, it could be noticed from the ninth day of storage that the snap bean of the Treatment 1 showed less darkening in relation to the other treatments, and also better accepted sensorially. It wasn't detected Salmonella and neither coliforms at $45^{\circ} \mathrm{C}$ in any sample of the different treatments. In relation to the total coliform counts, it could be noticed reduction with
\end{abstract}

\footnotetext{
${ }^{1}$ Bolsista Iniciação Científica FAPESP Proc. 2007/03558-1. E-mail: eduardo.peres@yahoo.com.br

${ }^{2}$ Pesquisador Científico da Agência Paulista de Tecnologia dos Agronegócios, Pólo Centro Oeste, Bauru, SP. E-mail: mcarruda@ apta.sp.gov.br; ihfische@apta.sp.gov.br

${ }^{3}$ Estagiária da Agência Paulista de Tecnologia dos Agronegócios, Pólo Centro Oeste, Bauru, SP. E-mail: msfileti@hotmail.com

${ }^{4}$ Prof ${ }^{a}$ da Universidade Sagrado Coração, Bauru/SP. E-mail: luan7@terra.com.br

${ }^{5}$ Estagiário da Agência Paulista de Tecnologia dos Agronegócios, Pólo Centro Oeste, Bauru, SP. E-mail: diegosvoltan@gmail.com

* Autor para correspondência
} 
the sanification (T2 and T3) on the processing day, and, in general, an increase in the coliform counts during the storage. The total bacteria count was $>10^{5} \mathrm{UFC}^{-1} \mathrm{~g}^{-1}$ in the snap bean of all treatments in the sixth day of storage, except in that one, which the snap beans were rinsed and sanitized. Therefore, this treatment is recommended and guarantee six days of shelf life for minimally processed snap bean, limited by the bacteria growth.

Key words: Phaseolus vulgaris L, minimal processing, chlorine, bacteria, darkening

\section{Introdução}

A crescente preocupação da população com a saúde tem levado ao aumento do consumo de frutas e hortaliças, ao mesmo tempo em que há uma demanda crescente por produtos convenientes. A indústria de alimentos tem respondido a essa demanda com o desenvolvimento dos produtos minimamente processados (VANETTI, 2000).

O feijão-vagem (Phaseolus vulgaris L.), também conhecido como vagem, é uma planta muito parecida com o feijoeiro que é cultivado e consumido como hortaliça. Possui mais proteína que qualquer outro alimento de origem vegetal e na sua composição são encontrados cálcio, fósforo, ferro e as vitaminas A, $\mathrm{B}_{1}, \mathrm{~B}_{2}$ e C (TESSARIOLI NETO; GROPPO, 1992).

A exploração comercial dessa cultura tem por finalidade o aproveitamento das vagens, produzidas pela planta, em seu estado imaturo. A ausência de fibrosidade na vagem permite a sua utilização na alimentação humana de várias formas, podendo ser industrializada ou consumida in natura (SPAGNOL, 2005).

A vagem minimamente processada é comercializadaisolada ou em diferentescombinações (cenoura/vagem; cenoura/vagem/batata). Apresenta como principal problema o escurecimento da superfície cortada ao longo do armazenamento. $\mathrm{O}$ escurecimento da vagem minimamente processada pode ser intensificado caso não seja realizada uma adequada eliminação dos exudatos celulares liberados após o processamento.

O escurecimento que se desenvolve na superfície onde a fruta ou hortaliça (principalmente as de coloração verde) é cortada é causado pelo contato da enzima polifenoloxidase (PPO) com compostos fenólicos na presença de oxigênio (KING; BOLIN, 1989; LAURILA; KERVINEN; AHVENAINEN, 1998).

A lavagem dos vegetais já cortados também é de suma importância por minimizar a proliferação microbiana e reduzir reações de escurecimento dos tecidos. A imersão dos produtos minimamente processados somente em água potável reduziu a contagem microbiana em aproximadamente 0,4 a 1,4 ciclos log de UFC. $\mathrm{g}^{-1}$ em rodelas de cenoura, pedaços de pimentão e cubos de batata; reduziu a contagem de Pseudomonas e enterobactérias psicrotróficas em aproximadamente 1 ciclo log em alface; reduziu a contagem de microrganismos totais e enterobactérias entre 0 e 0,5 ciclo log em saladas prontas para o consumo. Desta forma, conclui-se que a descontaminação resultante da lavagem somente em água dependerá do produto (PIROVANI; GÜEMES; PIAGENTINI, 2006). A sanificação dos produtos minimamente processados tem importante papel na diminuição da deterioração, na manutenção da qualidade e no aumento da vida de prateleira (SANTOS; VALLE, 2005). Tradicionalmente, os processadores utilizam água contendo sanificante para a lavagem dos produtos minimamente processados. Nesse caso, o cloro é, nas suas várias formas, o sanificante mais utilizado, em concentrações que variam de 50 a $200 \mathrm{mg} . \mathrm{L}-$ 1 (DYCHDALA, 1991, PIROVANI; GÜEMES; PIAGENTINI, 2006).

Spagnol (2005) observou uma redução de 2,62 ciclos log na contagem de coliformes e 1,29 ciclos log na contagem de bactérias psicrotróficas de vagens minimamente processadas, quando realizaram a sanificação em solução clorada (50 mg. $\left.\mathrm{L}^{-1}\right)$. 
A atividade antimicrobiana do cloro depende, dentre outros fatores, da quantidade de cloro livre disponível, particularmente em forma de ácido hipocloroso (HOCl) (DYCHDALA, 1991). Pelo fato do suco celular reagir com o cloro livre da solução sanificante, formando compostos indesejáveis e reduzindo sua eficiência, tem se enfatizado a necessidade de realização de um enxágue em água potável antes da imersão do produto minimamente processado em solução clorada (MORETTI; PUSCHMANN, 2006).

Spagnol (2005) recomenda para vagens, um enxágue após o corte, antes da operação de sanificação para evitar que o suco celular reaja com o cloro livre da solução sanificante, o que acarretaria em redução da sua eficiência. Este autor constatou enorme mudança na coloração da água de enxágue de vagens, devido à liberação do suco celular. Por outro lado, Pilon (2003) recomenda a sanificação logo após o processamento das vagens, sem prévio enxágue.

$\mathrm{Na}$ literatura, as pesquisas com vagens minimamente processadas envolvem a fisiologia do produto, embalagem e temperatura de armazenamento, havendo uma carência de informações no que diz respeito à influência das operações de enxágue e sanificação na qualidade de vagens minimamente processadas.

O objetivo deste trabalho foi avaliar a qualidade de vagens variedade Itatiba 2, minimamente processadas em função das operações de enxágue e sanificação.

\section{Material e Métodos}

\section{Processamento}

As vagens foram colhidas pela manhã na região de Botucatu e transportadas ao local de processamento, onde foram resfriadas em câmara a $10^{\circ} \mathrm{C}$ por aproximadamente 12 horas. Posteriormente foram submetidas às seguintes operações:
Seleção: quanto à ausência de danos mecânicos e podridões;

Lavagem: em água corrente para eliminação das sujidades mais grosseiras;

Sanificação: em solução clorada (100 mg L L $\left.\mathrm{L}^{-1}\right)$ por 5 minutos. $\mathrm{O}$ sanificante utilizado foi dicloroisocianurato de sódio;

Corte das extremidades: manualmente, com faca de inox;

Corte: em processador Robot Coupe, pedaços de aproximadamente $10 \mathrm{~mm}$ de comprimento.

Após o corte, as vagens minimamente processadas foram submetidas aos seguintes tratamentos:

T1 - enxágue somente em água;

T2 - enxágue em água, seguido de imersão em solução clorada (100 $\left.\mathrm{mg} \mathrm{L}^{-1}\right)$ por 5 minutos;

T3 - imersão em solução clorada (100 mg L-1) por 5 minutos;

T4 - sem enxágue e sem imersão em solução clorada (controle).

Posteriormente foram centrifugadas em centrífuga (700 rpm) por 45 segundos.

$\mathrm{O}$ acondicionamento foi feito em bandeja de poliestireno expandido $(14 \mathrm{x} 21 \mathrm{~cm})$ revestida por filme de PVC $10 \mu \mathrm{m}$ (aproximadamente $250 \mathrm{~g}$ de produto minimamente processado por bandeja) e o armazenamento foi realizado a $10^{\circ} \mathrm{C}$, simulando temperatura média das gôndolas de supermercados.

As vagens minimamente processadas foram avaliadas a cada três dias por período de 12 dias quanto à aparência geral, coloração da superfície de corte e aspectos microbiológicos.

\section{Delineamento experimental}

O delineamento utilizado foi inteiramente aleatorizado, em esquema fatorial (tratamentos $\mathrm{x}$ dias de análise). O número de repetições variou, de acordo com a variável analisada. 


\section{Descrição das análises}

a) Aparência geral: Para tanto foi aplicado um teste de aceitação com escala hedônica estruturada de 7 pontos, variando de 7 (gostei muitíssimo) a 1 (desgostei muitíssimo), sendo 4 o limite de aceitabilidade, conforme Ferreira et al. (2000). A equipe sensorial foi composta por 30 consumidores não treinados. As amostras de vagens minimamente processadas dos diferentes tratamentos foram apresentadas nas embalagens originais, codificadas com números de 3 dígitos. Cada consumidor recebeu uma bandeja de cada tratamento para avaliação.

b) Coloração da superfície de corte: foi determinada na mesma bandeja apresentada ao julgador durante a análise sensorial. Foram selecionados ao acaso 50 pedaços de vagem, os quais foram divididos em cinco lotes, sendo que cada lote de 10 pedaços representou uma repetição. Em cada pedaço foram realizadas duas leituras, em lados opostos, totalizando 20 leituras da superfície de corte para cada repetição de cada tratamento. As leituras foram realizadas em colorímetro Minolta, modelo CR-400, com resultados expressos em $\mathrm{h}^{\circ}$ (ângulo de cor hue). $\mathrm{O}^{\mathrm{o}}$ define a coloração básica, onde $0^{\circ}=$ vermelho, $90^{\circ}=$ amarelo e $180^{\circ}=$ verde (McGUIRRE, 1992). O ângulo hue é indicado para expressar o escurecimento de tecidos verdes por apresentar melhor correlação com a observação visual (Heimdal citado por Spagnol, 2005).

c) Aspectos microbiológicos: Foram realizadas análises de coliformes totais e coliformes a $45^{\circ} \mathrm{C}$, bactérias psicrotróficas e pesquisa de Salmonella, conforme recomendação de Silva et al. (2007). Foram avaliadas duas bandejas por tratamento. Os coliformes totais e a $45^{\circ} \mathrm{C}$ foram determinados pela técnica dos Tubos Múltiplos. As bactérias psicrotróficas foram determinadas através de plaqueamento em superfície em meio Ágar Padrão para Contagem (PCA), com incubação a $7^{\circ} \mathrm{C}$ por 10 dias. A análise de presença/ausência de Salmonella foi realizada através de método oficial 989.13 aprovado pela AOAC (Association of Official Analytical Chemists) para utilização em todos os tipos de alimentos, o qual utiliza o kit '1-2 test' fabricado pela Bio-control/USA. Esta análise foi realizada apenas no dia do processamento.

Os resultados de aparência geral e de coloração da superfície da casca foram submetidos à análise de variância e as médias comparadas pelo teste de Tukey (5\%), enquanto os resultados de coliformes e Salmonella foram comparados com a legislação vigente (BRASIL, 2001) e a pesquisa sobre bactérias psicrotróficas foi comparada com limites máximos estabelecidos para alimentos em geral (MORTON, 2001; CARUSO; CAMARGO, 1984).

\section{Resultados e Discussão}

Aparência geral

Em relação à aparência geral, as notas atribuídas às vagens do tratamento 1 foram significativamente maiores que as dos demais tratamentos. De modo geral, ao longo do tempo de armazenamento, os tratamentos apresentaram redução das notas médias atribuídas à aparência, sendo esta redução significativa a partir do sexto dia de armazenamento (Tabela 1).

No nono dia de armazenamento, as notas atribuídas à aparência das vagens do T2, T3 e T4 situaram-se entre 3,1-3,3 (desgostei), estando impróprias para a comercialização. Redução semelhante foi observada por Pilon (2003), que justifica essa diminuição das notas por conta do escurecimento das vagens. 
Tabela 1. Médias das notas ${ }^{1}$ de aceitação para o atributo aparência geral das vagens minimamente processadas em função das operações de enxágue e sanificação.

\begin{tabular}{lccccc}
\hline \multirow{2}{*}{ Tratamentos } & \multicolumn{5}{c}{ Dias de Armazenamento $10^{\circ} \mathrm{C}$} \\
\cline { 2 - 6 } & 3 & 6 & 9 & 12 & Nota média \\
\hline Enxágue (T1) & 4,83 & 4,47 & 4,27 & 4,33 & $4,48 \mathrm{a}$ \\
Enxágue + Sanificação (T2) & 4,93 & 3,90 & 3,30 & 3,50 & $3,91 \mathrm{~b}$ \\
Sanificação (T3) & 4,90 & 3,83 & 3,10 & 3,17 & $3,75 \mathrm{~b}$ \\
Controle (T4) & 4,17 & 3,67 & 3,23 & 3,13 & $3,55 \mathrm{~b}$ \\
\hline Nota média & $4,71 \mathrm{~A}$ & $3,97 \mathrm{~B}$ & $3,48 \mathrm{C}$ & $3,53 \mathrm{C}$ & -- \\
\hline
\end{tabular}

${ }^{1}$ Notas: 7=gostei muitíssimo; 6=gostei muito; 5=gostei; 4=não gostei, nem desgostei; 3=desgostei; 2=desgostei muito; 1=desgostei muitíssimo

Médias seguidas de mesma letra maiúscula na linha e minúscula na coluna não diferem entre si ao nível de 5\% de probabilidade.

\section{Coloração da superficie de corte}

Em relação à coloração da superfície de corte, houve redução do ângulo hue na superfície de corte de todos os tratamentos, ocorrendo escurecimento gradativo ao longo do tempo. Porém, somente a partir do nono dia de armazenamento, observou-se diferença $(\mathrm{P}<0,05)$ entre os tratamentos, onde as vagens do Tratamento 1 apresentaram maior ângulo hue, ou seja, menor escurecimento em relação à dos demais tratamentos (Tabela 2).

Tabela 2. Coloração da superfície de corte $\left({ }^{\circ}\right.$ hue) das vagens minimamente processadas em função das operações de enxágue e sanificação.

\begin{tabular}{lccccc}
\hline \multirow{2}{*}{ Tratamentos } & \multicolumn{5}{c}{ Dias de Armazenamento $10^{\circ} \mathrm{C}$} \\
\cline { 2 - 6 } & 0 & 3 & 6 & 9 & 12 \\
\hline Enxágue (T1) & $117,38 \mathrm{Aa}$ & $112,97 \mathrm{Ba}$ & $110,31 \mathrm{Ca}$ & $109,40 \mathrm{Da}$ & $107,26 \mathrm{Da}$ \\
Enxágüe + Sanificação (T2) & $117,15 \mathrm{Aa}$ & $113,46 \mathrm{Ba}$ & $109,17 \mathrm{Ca}$ & $106,00 \mathrm{Db}$ & $104,83 \mathrm{Db}$ \\
Sanificação (T3) & $116,77 \mathrm{Aa}$ & $111,31 \mathrm{Ba}$ & $108,12 \mathrm{Ca}$ & $104,73 \mathrm{Db}$ & $103,20 \mathrm{Db}$ \\
Controle (T4) & $116,62 \mathrm{Aa}$ & $111,29 \mathrm{Ba}$ & $108,47 \mathrm{Ca}$ & $105,05 \mathrm{Db}$ & $103,37 \mathrm{Db}$ \\
\hline
\end{tabular}

Médias seguidas de mesma letra maiúscula na linha e minúscula na coluna não diferem entre si ao nível de 5\% de probabilidade.

Estes resultados indicam que tanto cloro como o exsudato celular (mantido nas vagens do tratamento 4) afetaram a coloração da superfície de corte das vagens, intensificando o escurecimento.

Spagnol (2005), também observou que a coloração da face de corte das vagens minimamente processadas tornou-se escurecida durante $\mathrm{o}$ armazenamento a $5^{\circ}$ e $11^{\circ} \mathrm{C}$. Segundo King e Bolin (1989) e Laurila, Kervinen e Ahvenainen (1998), possivelmente esta coloração está relacionada com reações enzimáticas causada pela polifenoloxidase (PPO). Este escurecimento se desenvolve na superfície onde a fruta ou hortaliça (principalmente as de coloração verde) é cortada, e é causado pelo contato da PPO com compostos fenólicos na presença de oxigênio. A PPO corresponde a um termo genérico empregado para um grupo de enzimas que, pela suas ações, causam a conversão de compostos fenólicos em substâncias com coloração marrom ou pretas chamadas de "melaninas".

A manutenção de coloração natural de hortaliças é muito importante após seu processamento. A identificação como um produto fresco aumenta a aceitabilidade do consumidor (FÁVARO, 2000). 


\section{Aspectos microbiológicos}

Salmonella e coliformes a $45^{\circ} \mathrm{C}$ não foram detectados em nenhuma amostra dos diferentes tratamentos, estando, portanto, dentro dos padrões estabelecidos pela RDC $\mathrm{n}^{\circ} 12$ da ANVISA de 02 de janeiro de 2001, a qual estabelece para hortaliças minimamente processadas ausência de Salmonella em 25 g e máximo de $10^{2} \mathrm{NMP} \mathrm{g}^{-1}$ de coliformes a $45^{\circ} \mathrm{C}$.
Em relação à contagem de coliformes totais observou-se no dia do processamento redução com a sanificação (T2 e T3) e em geral, aumento dos coliformes durante o armazenamento. Entretanto, os valores mantiveram-se baixos $\left(\leq 2,1 \times 10^{2}\right)$ em todos os tratamentos (Tabela 3), evidenciando as boas práticas agrícolas, de manuseio e de processamento adotadas.

Tabela 3. Coliformes totais em vagens minimamente processadas em função das operações de enxágue e sanificação.

\begin{tabular}{llcccc}
\hline \multirow{2}{*}{ Tratamentos } & \multicolumn{5}{c}{ Dias de Armazenamento $10^{\circ} \mathrm{C}$} \\
\cline { 2 - 5 } & 0 & 3 & 6 & 9 & 12 \\
\hline Enxágue (T1) & $0,92 \times 10^{1}$ & $9,3 \times 10^{1}$ & $9,3 \times 10^{1}$ & $2,10 \times 10^{2}$ & $9,3 \times 10^{1}$ \\
Enxágue + Sanificação (T2) & $0,36 \times 10^{1}$ & $2,3 \times 10^{1}$ & $4,3 \times 10^{1}$ & $<0,3$ & $1,5 \times 10^{2}$ \\
Sanificação (T3) & $0,36 \times 10^{1}$ & $2,1 \times 10^{1}$ & $9,3 \times 10^{1}$ & $1,6 \times 10^{1}$ & $0,92 \times 10^{1}$ \\
Controle (T4) & $4,3 \times 10^{1}$ & $2,3 \times 10^{1}$ & $1,5 \times 10^{2}$ & $2,9 \times 10^{1}$ & $2,9 \times 10^{1}$ \\
\hline
\end{tabular}

Vagem antes do processamento: $0,92 \times 10^{1}$

Os resultados obtidos representam a média aritmética do NMP ( $\mathrm{n}^{\circ}$ mais provável)/ $\mathrm{g}$ de produto

Quanto à contagem de bactérias psicrotróficas, observa-se no dia do processamento que as vagens dos tratamentos 2 e 3 apresentaram menor contaminação, com contagens de aproximadamente 2 ciclos menor que as vagens do $\mathrm{T} 1 \mathrm{e}$ aproximadamente 1 ciclo log menor que as vagens do T4 (Tabela 4), evidenciando a eficácia do cloro. Spagnol (2005) observou uma redução 1,29 ciclos log na contagem de bactérias psicrotróficas de vagens minimamente processadas, quando realizou a sanificação em solução clorada (50 mg. $\mathrm{L}^{-1}$ ). No terceiro dia de armazenamento, as vagens do tratamento controle atingiram contagens da ordem de $10^{5} \mathrm{UFC}^{-1} \mathrm{~g}^{-1}$ enquanto as vagens dos demais tratamentos apresentaram neste dia contagens da ordem de $10^{4}$. No sexto dia de armazenamento apenas o tratamento 2 (enxágue + sanificação) apresentou contagem menor que $10^{5}$. Os demais tratamentos apresentaram contagens acima deste valor. No nono dia de armazenamento o T2 também apresentou contagem acima de $10^{5}$. A maior efetividade do $\mathrm{T} 2$ ao longo do armazenamento provavelmente seja devido ao maior residual de cloro nas vagens onde houve eliminação do exsudato celular (enxágue).

Tabela 4. Bactérias psicrotróficas em vagens minimamente processadas em função das operações de enxágue e sanificação.

\begin{tabular}{llllll}
\hline \multirow{2}{*}{ Tratamentos } & \multicolumn{5}{c}{ Dias de Armazenamento $10^{\circ} \mathrm{C}$} \\
\cline { 2 - 5 } & 0 & 3 & 6 & 9 & 12 \\
\hline Enxágue (T1) & $1,42 \times 10^{4}$ & $7,35 \times 10^{4}$ & $8,65 \times 10^{5}$ & $5,9 \times 10^{5}$ & $5,15 \times 10^{5}$ \\
Enxágue + Sanificação (T2) & $8,5 \times 10^{2}$ est & $5,55 \times 10^{4}$ & $8,5 \times 10^{4}$ & $3,95 \times 10^{5}$ & $3,7 \times 10^{6}$ \\
Sanificação (T3) & $3 \times 10^{2}$ est & $2,3 \times 10^{4}$ & $2,65 \times 10^{6}$ & $1,16 \times 10^{6}$ & $4,6 \times 10^{5}$ \\
Controle (T4) & $1,55 \times 10^{3}$ & $7,2 \times 10^{5}$ & $1,05 \times 10^{7}$ & $2,42 \times 10^{6}$ & $1,2 \times 10^{7}$ \\
\hline
\end{tabular}

Vagem antes do processamento: $9,45 \times 10^{3}$

Os resultados obtidos representam a média aritmética de UFC (unidades formadoras de colônias) / g de produto est $=$ valores estimados 
A contagem de bactérias psicrotróficas não está diretamente relacionada à presença de patógenos. Na legislação não há limites máximos de bactérias psicrotróficas para produtos minimamente processados. Porém, vários autores consideram que alimentos com contagens da ordem de $10^{5}-10^{6}$ são impróprios para o consumo devido aos riscos de presença de patógenos e/ou deterioradores. (MORTON, 2001; CARUSO; CAMARGO, 1984). Portanto no nono dia de armazenamento as vagens de todos os tratamentos apresentavam-se impróprias para o consumo.

\section{Conclusões}

Após o processamento as vagens devem ser enxaguadas em água potável e em seguida sanificadas em solução clorada (100 mg.L $\left.{ }^{-1}\right)$ por 5 minutos. Dessa forma as vagens minimamente processadas acondicionadas em bandeja de poliestireno expandido revestida por filme de PVC $10 \mu \mathrm{m}$ e armazenada a $10^{\circ} \mathrm{C}$ apresentam vida útil de até seis dias. A vida útil é limitada pelo crescimento de bactérias e escurecimento da superfície de corte.

\section{Agradecimentos}

$\mathrm{O}$ primeiro autor agradece à Fapesp pela concessão da bolsa de Iniciação Científica.

\section{Referências}

BRASIL. Resolução RDC n. 12 de 02 de janeiro de 2001 da Agência Nacional de Vigilância Sanitária. Dispões sobre o Regulamento técnico sobre padrões microbiológicos para alimentos. Diário Oficial da República Federativa do Brasil, Brasília, DF, 10 de jan. 2001

CARUSO, J. G. B.; CAMARGO, R. Microbiologia de alimentos. In: CAMARGO, R. (Ed.). Tecnologia dos produtos agropecuários - alimentos. São Paulo: Nobel, 1984, p. 35-49.

DYCHDALA, G. R. Chlorine and chlorine compounds. In: BLOCK, S. S.; BARKLEY, W. E. (Ed.). Desinfection sterilization and preservation. $4^{\text {th }}$ ed. Philadelphia: Lea \& Febiger, 1991. p. 131-151.
FÁVARO, S. P. Cor de feijão vagem fresco e processado após aplicação de cálcio. Scientia Agrícola, Piracicaba, v. 57, n. 3, p.561-563, 2000.

FERREIRA, V. L. P.; ALMEIDA, T. C.A.; PETTINELLI, M. L. C. V.; SILVA, M. A. A. P.; ChAVES, J. B. P.; BARBOSA, E. M. M. Análise sensorial: testes discriminativos e afetivos. Campinas: SBCTA, 2000.127 p.

KING, A. D.; BOLIN, H. R. Physiological and microbiological storage stability of minimally processed fruits and vegetables. Food Technology, Chicago, v. 43, n. 2, p. 132-135, 1989.

LAURILA, E.; KERVINEN, R.; AHVENAINEN, R. The inhibition of enzymatic browning in minimally processed vegetables and fruits. Postharvest News and Information, Wallingford, v. 9, n. 4, p. 53-66, 1998.

McGUIRRE, R. G. Reporting of objective color measurents. HortScience, Alexandria, v. 27, n. 12, p. 1254-1255, 1992.

MORETTI, C. L.; PUSCHMANN, R. Processamento Mínimo de Hortaliças. In: ENCONTRO NACIONAL SOBRE PROCESSAMENTO MÍNIMO DE FRUTAS E HORTALIÇAS, 4., 2006, São Pedro. Palestras, Resumos, Fluxogramas e Oficinas... Piracicaba: ESALQ, 2006. p. 234-239.

MORTON, R. D. Aerobic plate count. In: DOWNES, F. P.; ITO, K. (Ed.). Compendium of methods for the microbiological examinations of foods. Washington: American Public Health Association, 2001. p. 63-67.

PILON, L. Estabelecimento da vida útil de hortaliças minimamente processadas sob atmosfera modificada e refrigeração. 2003. Dissertação (Ciência e Tecnologia de Alimentos) - Escola Superior de Agricultura "Luiz de Queiroz". Universidade de São Paulo, Piracicaba.

PIROVANI, M. E.; GÜEMES, D. R.; PIAGENTINI, A. M. Lavado desinfección com soluciones cloradas: Una etapa para mejorar la calidad microbiológica de vegetales de hoja frescos cortados. In: SIMPOSIO IBEROAMERICANO DE VEGETALES FRESCOS CORTADOS, 1., São Pedro, 2006. Palestras... São Pedro: Sonora, CYTED, p. 23-28, 2006.

SANTOS, H. P.; VALLE, R. H. P. do. Influência da sanificação sobre a qualidade de melão amarelo minimamente processado: parte II. Ciência e Agrotecnologia, Lavras, v. 29, n. 5, p. 1034-1038, 2005.

SILVA, N. da.; JUNQUEIRA, V. C. A.; SILVEIRA, N. F. A.; TANIWAKI, M. H.; SANTOS, R. F. S.; GOMES, R. A. Manual de métodos de análise microbiológica de alimentos. 3. ed. São Paulo: Varela, 2007. 552 p. 
SPAGNOL, W. A. Processamento mínimo de cenoura e feijão-vagem. 2005. Tese (Doutorado em Tecnologia Pós-Colheita) - Faculdade de Engenharia Agrícola. Universidade de Campinas, Campinas.

TESSARIOLI NETO, J.; GROPPO, G. A. A cultura do feijão-vagem. Campinas: Coordenadoria de Assistência Técnica Integral, 1992. 12 p. (Boletim Técnico, 212).
VANETTI, M. C. D. Controle microbiológico e higiene no processamento mínimo. In: ENCONTRO NACIONAL SOBRE PROCESSAMENTO MÍNIMO DE FRUTAS E HORTALIÇAS, 2., 2000, Viçosa. Palestras....Viçosa: UFV, 2000. p. 44-52. 